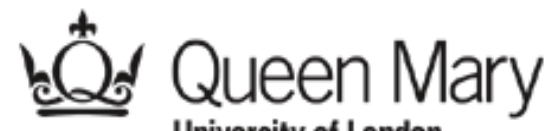 \\ University of London
}

Centre for Globalization Research

School of Business and Management

\section{(How) Do Non-Cognitive Skills Programs Improve Adolescent School Achievement? Experimental Evidence}

\author{
CGR Working Paper 81
}

Pedro S. Martins

\begin{abstract}
Non-cognitive skills programs may be an important policy option to improve the academic outcomes of adolescents. In this paper, we evaluate experimentally the EPIS program, which is based on relatively short bi-weekly individual or small-group non-cognitive mediation meetings with students selected based on their low school achievement. Our RCT estimates, covering nearly 3,000 7th- and 8th-grade students across over 50 schools and two years, indicate that the program increases the probability of progression by $11 \%$ to $22 \%$. The effects are stronger amongst older students, girls, and in language subjects, and when the program mediator is of the same gender as the student.
\end{abstract}

Keywords: Student achievement, Non-cognitive skills, RCT, Matched School-Student Data.

JEL codes: I20, I24, J08

http://www.busman.qmul.ac.uk/cgr 


\title{
(How) Do Non-Cognitive Skills Programs Improve Adolescent School Achievement? Experimental Evidence*
}

\author{
Pedro S. Martins ${ }^{\dagger}$ \\ Queen Mary University of London \& NovaSBE \& IZA
}

April 2, 2017

\begin{abstract}
Non-cognitive skills programs may be an important policy option to improve the academic outcomes of adolescents. In this paper, we evaluate experimentally the EPIS program, which is based on relatively short bi-weekly individual or small-group non-cognitive mediation meetings with students selected based on their low school achievement. Our RCT estimates, covering nearly 3,000 7th- and 8th-grade students across over 50 schools and two years, indicate that the program increases the probability of progression by $11 \%$ to $22 \%$. The effects are stronger amongst older students, girls, and in language subjects, and when the program mediator is of the same gender as the student.
\end{abstract}

Keywords: Student achievement, Non-cognitive skills, RCT, Matched School-Student Data.

JEL Codes: I20, I24, J08.

\footnotetext{
*I thank Diogo Simões Pereira and Andreia Jaqueta Ferreira for many discussions, Bruno Leal for information about the data, and EPIS 2017 conference participants for their questions and suggestions. Special thanks to Roberto Carneiro for his support. The views and results presented here are my own and not necessarily those of EPIS. Any errors are also of my responsibility only.

${ }^{\dagger}$ Email: p.martins@qmul.ac.uk Address: School of Business and Management, Queen Mary, University of London, Mile End Road, London E1 4NS, United Kingdom. Phone: +44/0 2078827472. Web: http://webspace.qmul.ac.uk/pmartins.
} 


\section{Introduction}

Low achievement levels at basic schooling can have significant negative effects upon one's human capital, labour market outcomes, and children (Heckman \& Carneiro 2003, Black \& Devereux 2011). From a macroeconomic perspective, economic growth can also suffer greatly from low (and low quality) schooling achievement (Krueger \& Lindahl 2001, Hanushek et al. 2015).

A number of programs have consequently been launched by governments around the world to enhance the outcomes of those at the bottom of the schooling achievement distribution, in particular in the case disadvantaged pupils. These programs typically involve some form of remedial education, based on additional tuition, revision sessions, computer-aided learning, etc. However, the causal effects of many of these programs have been shown to be large (Lavy \& Schlosser 2005, Dobbie \& Fryer 2011, Cortes et al. 2015), small (Machin et al. 2004), mixed (Jacob \& Lefgren 2004, Taylor 2014), or insignificant (Leuven et al. 2007). Similar mixed findings have been obtained for the case of developing countries (Glewwe \& Kremer 2006, Banerjee et al. 2007).

While all programs above focus on cognitive skills (e.g. revising class room material), economists have over the last few years devoted more attention to the potential of a noncognitive approach (Heckman \& Rubinstein 2001, Heckman et al. 2006). In fact, such 'softer' aspects of one's profile may be equally important in shaping one's success at school and beyond: motivation, discipline, tenacity, self-esteem, self-control, confidence, patience, etc. In this context, school interventions based on non-cognitive skills may be at least or even more effective than the more traditional remedial programs, as the ones listed above. As argued by Heckman \& Kautz (2012), 'soft skills causally produce success in life', with the implication that 'programs that enhance soft skills have an important place in an effective portfolio of public policies'. Moreover, as the relative payoff of investments in hard and soft skills tends to tilt towards the latter with age (Heckman \& Cunha 2007), despite their substitutability and complementarity, adolescence may be a key juncture when to deploy non-cognitive interventions.

This paper sheds empirical light on these issues as one of the first to evaluate experimentally the effects of a large soft-skills program for adolescents (see Kautz et al. (2014) for a description of the existing literature). Moreover, we also seek to shed light on the mechanisms 
behind such effects (if any). We consider the case of EPIS, an original program that seeks to improve student achievement and reduce retention and early school leaving of lower-secondary students by strengthening their non-cognitive skills. On top of the emphasis placed on noncognitive skills, EPIS is original due to its rigorous screening of all student participants. Such screening ensures that the resources invested by the program - mostly the staff (mediators) time, typically devoted to 20-minute small-group or one-to-one sessions with selected students, every two or three weeks during term time - are spent exclusively on the youngsters that are likely to need the most. In fact, although many education programs have been shown to have small or insignificant effects, 'inputs specifically targeted to helping weaker students may be effective', in particular 'if they address specific unmet needs in the school' (Banerjee et al. 2007).

Although such screening typically raises challenges in the identification of the causal effects, here we draw on evidence from a randomised controlled trial launched in 2014 and driven by restrictions in the number of staff available in a large number of schools. By selecting randomly the students that participate out of all those who are eligible following the screening process, we are able to establish a rigorous counterfactual in the impact of interest. We also add to the original quasi-experimental evidence for the period 2007-09 (Martins 2017).

Our evidence indicates that, unlike many remedial programs, an intervention based on non-cognitive interventions such as EPIS can have a significant, positive effect in terms of improving the achievement levels of treated students. According to our findings, the probability that a student has a satisfactory performance over a period of two years (defined here as no retention) increases by 5 to 10 percentage points or, equivalently, by 11 to 22 percent. However, we also find that the effects of the program on specific modules that may be more intensive in cognitive skills (e.g. maths) tend to be smaller, even if still significant in some specifications. This latter result may highlight the limitations of an approach based almost entirely on non-cognitive skills; it may also reconcile our results with those of the only other large and recent case-study of non-cognitive skills for adolescents we are aware of (Holmlund \& Silva 2014), which find insignificant results in a quasi-experimental analysis.

Our results also provide evidence on the mechanisms behind the creation of these effects. For instance, we find that, while mediator characteristics are generally not relevant, the matching of the mediators and the students matters, particularly in terms of their gender. 
We also find that older students tend to benefit more from these non-cognitive interventions. The programme is also more successful in languages than in maths, perhaps because of the stronger cognitive content of the latter subject.

The structure of the paper is as follows: Section 2 describes the main characteristics of the program studied in the paper and its institutional context; Section 3 presents the matched school-student panel data set used in this paper and a number of descriptive statistics; Section 4 describes the main results and several robustness checks and extensions. Finally, Section 5 concludes.

\section{The EPIS program}

The main goals of the EPIS program are to reduce early school leaving and to promote student achievement 11 These are important policy goals in many countries, including in Portugal, where at the time when the program was introduced, 2007, 39.1\% of 18-24 year olds had at most a lower secondary school degree and were not enrolled in any training. This was related to the high levels of retention rates in schools, at about $15 \%$ in each of the three years of the lower secondary cycle (7th, 8th, and 9th grades).

The goals of program are pursued through an original intervention in that EPIS aims to strengthen the non-cognitive skills of students - in striking opposition to a more standard remedial approach, based on cognitive skills. As mentioned before, there is growing awareness about the potential effects of such non-cognitive skills - motivation, discipline, tenacity, selfesteem, self-control, confidence, patience, etc - in terms of different socio-economic outcomes (Heckman \& Rubinstein 2001, Heckman et al. 2006) but also mixed evidence about the effects of these programs in terms of student achievement (Holmlund \& Silva 2014).

From a practical point of view, one important dimension of the EPIS program is its adoption of a targeted approach. Specifically, EPIS spends considerable effort in identifying the 7th- and 8th-grade pupils (typically 13-15 year-olds) most at risk of failing their year and/or dropping out. This process involves at least two rounds of screening, first when students are interviewed individually by EPIS staff, and second through a number of meetings of EPIS staff (mediators) with teachers, headteachers and parents for further information

\footnotetext{
${ }^{1}$ The program's name is 'Mediators for school success'. However, we refer to the program using the name of the organisation that is responsible for it (EPIS, 'Entrepreneurs for Social Inclusion'), a private, not-for-profit organisation.
} 
about the students. A detailed questionnaire is applied to each student, which leads to the assignment of the student to one of three different levels of students' low achievement likelihood and potential dropping out. Students that are in the highest risk group (in terms of low achievement) are then assigned to the program (on average about one third of all 7 th and 8th grade students in each school). Students that are in the intermediate group are referred to their teachers for further monitoring. The remaining group of students are disregarded by the program, except that their grades are also recorded, up to their graduation from lower secondary school (9th grade) or when they leave school (whichever the earliest).

Once the students' parents agree on the participation of their children (which approximately $95 \%$ do), then a mediator and a specific set of interventions is assigned to each student. These methods will depend on the individual non-cognitive, behavioral or other issues that are flagged during the screening process. The intervention will therefore implement one or more different approaches, namely individual techniques (motivational discussions, self-control, problem-solving techniques), and group techniques (study methods, social competences training, management of criticism, anxiety self-control).

These one-to-one or small-group interventions are implemented by EPIS staff (mediators) that work full- or part-time in the program and are based permanently at the participating schools (see Figure 1 for an illustration of a one-to-one session in progress in a participating school). EPIS staff also seek to keep in frequent contact with the relatives and teachers of the participating students and, in some cases, their local councils, to monitor the progress of each intervention pupil as closely as possible. In fact, EPIS staff not only meet their students individually or in very small groups but they also do so on a relatively frequent basis (e.g., every two weeks). During the first meetings, staff and students agree on goals with respect to each student's future performance. Meetings typically do not overlap with classes, in particular in the core subjects, so to minimise negative effects on class attendance. Many such staff are young graduates in psychology or education sciences; in the case of the schools which we evaluate in this paper, the program is delivered by tenured teachers that have reduced teaching duties on account of demographic reasons.

Furthermore, the program seeks to promote a stable mediator-student relationship, as that can strengthen the effect of the treatment. Over the period and sample studied here, there are 57 EPIS staff working in 53 schools. Each full-time mediator holds a portfolio of 
approximately 60 students, typically in one school only. Part-time mediators will have the size of their portfolio reduced on a proportional basis. All mediators also take part in several training sessions before they are allocated to schools and during the program $2^{2}$

On an administrative level, the program's funding comes from approximately 100 large companies and organisations based in Portugal, each paying an annual contribution of 15,000 euros in the context of their corporate social responsibility activities. (A small share of these funds are spent on additional initiatives, including traineeships, scholarships, and a training program for lower primary teachers.) In addition, a scientific council formed by academic experts in education, psychology and economics contributed towards the design of the program studied here, also meeting regularly to offer comments and suggestions to senior EPIS staff. 3

The Ministry of Education and the local councils where the interventions are taking place also offer additional, generally non-financial, support, namely in terms of facilities at schools, coordination with headteachers, and program staff (the latter only in a number of cases, including the program stream studied here). EPIS also received the public endorsement of the President of Portugal, while several newspapers and TV stations agreed to advertise the program on a pro bono basis, to raise the public awareness and profile of the program, thus facilitating its implementation in schools, in terms of greater support by teachers, parents and students.

\section{$3 \quad$ Data and descriptive statistics}

The EPIS program adopted a sophisticated IT system that keeps detailed longitudinal records of students. In particular, there are individual records about all students from each school that takes part in the program, including those that are not subject to the interventions, provided they are also enrolled in the 7th or 8th grades. Most information, including the students' grades, is recorded at the term frequency, corresponding to the three terms per school year: September to December, January to March, and April to June.

The data include several demographic variables about each student, such as gender and age, and different profile characteristics, in particular a number of proxies of socio-economic or

\footnotetext{
${ }^{2}$ See Pereira et al. (2008) for detailed information about the program, in particular the psychological contents of the interventions conducted in one-to-one or small-group meetings, and Martins (2017), which studies an earlier period of this program, drawing on quasi-experimental evidence. See also http://www.epis.pt (in Portuguese) for more detail about the program and its initiatives and data access.

${ }^{3}$ The author has been an unpaid member of this scientific council since its inception, in 2006, and its president since 2014 .
} 
psychological issues that may affect progression. Interviews with teachers result in additional information from previous school years of each student, including about potential earlier spells of retention.

As all information is longitudinal, we create a matched multilevel panel, covering the student, the class (group of students that take the modules together during each school year), the EPIS mediator, and the school, with unique and time-invariant identifiers for each one of those four levels. Moreover, we also draw on information on the meetings of the mediators with the students.

The randomised controlled trial conducted in this paper is based on a group of 53 schools followed over two school years, 2014/15 and 2015/16. As indicated above, these schools participated in the program following a partnership between EPIS and the Ministry of Education in which the latter assigned a number of teachers that could assign all or some of their time to the program. However, in most cases, the number of teachers available - and the corresponding number of students that can be supported through their participation, on a basis of around 60 students per full-time teacher/mediator - fell short of the number of students signalled as being in risk of low achievement or retention following the screening process conducted by EPIS at the beginning of the school year. This mismatch between resources and needs is described in Figure 2 which presents the number of signalled and treated students per school. The figure displays a set of schools along a diagonal line that corresponds to cases in which available resources were enough to meet intervention needs. The figure also display an additional set of schools in which resources fell short of needs. The latter case corresponds to over two thirds of all, nearly 3,000, students signalled and 32 schools. Our randomisation was then conducted across the latter group of schools and their students, at the level of the school.

Given the above, the number of students supported varies across schools depending on the number of students signalled and the amount of time available for mediation by the teachers. In some cases, all signalled students were assigned to receive the intervention. In other cases, only $50 \%$ or less of the students did so. Moreover, as the randomisation was conducted at the school level, the number of treated students can also vary across classes within a school.

Table 1 presents descriptive statistics about the resulting treatment and control groups, composed of 2,311 and 648 students, respectively, and measured in the first term of the 2014/15 
academic year (i.e. just before the interventions start, typically in March 2015). Focusing on the case of the treatment group, the students' average age is $14,46 \%$ are girls, the average class size is 22 and $12 \%$ of the students are in vocational classes. The average school year is 7.5 , indicating that half of the group is in the 7 th grade and the remaining half is in the 8 th grade.

A number of screening indicators is also presented, as well as a number of measures of student achievement, namely the number of fail grades in the first and second terms of 2014/15 as well as the specific (pass or fail) grades in the core subjects of maths, Portuguese and English. Out the twelve modules in which students are enrolled in both the 7th and 8th grade, we find that the students in the treatment group fail an average of 4.8 in the first term and 4.4. in the second term. These are very large numbers of fails, in particular given that, in general, students are retained (i.e. cannot progress) when they fail three or more modules in the third and final term of the year. Moreover, the assessment in the third term is supposed to reflect not only the student's performance in that term but also the overall performance across the three terms. This implies that poor performance in the first and second terms will already create a (very) negative outlook for the final and decisive term. In addition, when considering the key modules of maths, Portuguese and English, one finds that the performance of the students in the treatment group is also particularly poor, especially in maths, in which three quarters or more of the students fail.

One final but critical point in the table concerns the comparison between the characteristics of the treatment group and the control group. As expected given the randomisation of assignment, these characteristics are equal from a statistical perspective along most dimensions considered in the table. However, note that here the comparisons are conducted across the two groups whereas the randomisation was conducted within schools. Indeed, when considering each variable in turn in a regression with school fixed effects (the dimension at which the randomisation was conducted) we again find virtually no cases of statistically significant differences between treatment and control groups (results available upon request).

We now turn to Table 2, which presents a similar comparison but between the signalled group of students (which corresponds to students in either the control or treatment groups) and the non-signalled students (i.e. those that are deemed to have relatively good prospects of achievement, following the same screening process conducted by EPIS mediators across 
all students in the participating schools). Although the latter are not considered in the main analysis in this paper, it is important to highlight the differences between the two groups, given the selection focus of the program. In striking contrast to the previous table, the comparison now indicates very marked and significant differences in virtually all variables. For instance, non-signalled students are nearly one year younger than their signalled counterparts. They are in larger classes, with 23.7 students on average (compared to 22.3 in the case of signalled students) and less likely to be in vocational groups.

Even more striking differences are observed in the screening scores and the indicators of student achievement. Focusing on the latter, where in the case of signalled students, the average number of fail marks is 4.8 , the equivalent number for non-signalled students is only 1.9. Where in the former case, $77 \%$ of students fail maths, this percentage drops to $39 \%$ in the case of non-signalled students. Overall, these large differences in characteristics and school performance highlight the important of an experimental approach, to ensure one is able to focus exclusively on the role of the program and not of other differences between treatment and control groups.

\section{Results}

We estimate the main effects of the introduction of the EPIS program from student achievement equations, in the context of a linear probability model. Specifically, we estimate equations as follows:

$$
y_{i}=\beta_{1} E P I S_{i}+\gamma_{s(i)}+u_{i},
$$

in which, in most specifications, $y_{i}$ is a variable referring to student $i$ that takes value one if the student progressed over both the academic years 2014/15 and 2015/16 (i.e. if the student experienced no retention over those two academic years). Moreover, EPIS $i t$ is a dummy variable equal to one if student $i$ is assigned to the treatment group (intention to treat approach) or if the student participated in the program (following assignment). Finally, $\gamma_{s(i)}$ is a set of school fixed effects, the level at which the randomisation was conducted, as explained above, corresponding to the school of student $i$.

Our main results are presented in Table 3, considering two alternative program indicator variables and three different samples, in specifications without any control variables other 
than the school fixed effects. In our main intention-to-treat estimates, we find that program assigment led to an increase in progression over the two years (from 2014/15 to 2015/16) of 4.8 percentage points (column 1). Given a reference probability of $45 \%$ for the comparison group, of eligile students that were not assigned to the program, this effect can be interpreted as an increase of $11 \%$ in the probability of progression. This coefficient is significant at the $10 \%$ level and almost at the $5 \%$ level (p-value of $6 \%$ ). This result also holds when restricting the sample to students that are observed over the two-year period (column 2).

Table 3 also presents two complementary estimates, focused on program delivery, i.e. when we reassign from the treatment group those students who declined to participate either to the control group - column 3 - or removing them from the sample - column 4 . In these cases, the resulting estimates increase, to .099 or .061, and become significant at the $1 \%$ and $5 \%$ levels, respectively. In the more generous case, the program has an effect of increasing progression by as much as $22 \%(.099 / .45)$. Overall, these main experimental results indicate that the EPIS program has an important causal effect in terms of promoting student achievement, with effects ranging between $11 \%$ and $22 \%$.

The following tables investigate the robustness of these findings, considering different sets of control variables, different groups of students, different outcomes and, finally, the role of mediators. First, Table 4 presents a set of findings under the two EPIS variables (assignment and delivery) and three sets of control variables. Here, we consider an extended model of equation 1, as follows:

$$
y_{i}=\beta_{1} E P I S_{i}+X_{i}^{\prime} \beta_{2}+\gamma_{s(i)}+u_{i}
$$

in which $X$ corresponds to different sets of control variables, including age, gender, class size, screening scores, and grades.

Again, we find in all cases evidence of positive, large, and statistically significant results. These range between .053 and .077 in the case of the EPIS assignment variable and between .097 and .086 in the case its delivery version. As expected under random assignment, while the magnitude of the EPIS coefficients is similar to the results of Table 3 , the significance of the coefficients increases as we add regressors that help explain the outcome variable.

The coefficients of the control variables are of interest too, from the more general perspective of the literature on the determinants of student achievement (Lazear 2001, 2003, Rivkin et al. 2005, Aaronson et al. 2007, Lavy 2009, Martins \& Walker 2006). We find that girls 
have significantly better results, with effects of a magnitude similar to that of EPIS (in its assignment version), an issue that will be revisited at the end of the paper. Age (considered using a quadratic specification) appears to have a moderate non-linear effect but the coefficients are in general not significant. Importantly, the progression probability is much higher for students in the 8 th grade than their colleagues in the 7th grade. Finally, class size appears to have a negative effect on student progression, with coefficients of about - $1 \%$ per additional student. Taking the latter result at face value, they imply that the EPIS program can be seen to be equivalent to a reduction of four to five students per class, in terms of their effects on the progression of the targeted students.

Finally, we consider the results of the screening variables (used for establishing eligibility, as described above) and that of student performance at the start of the program. We find that, as expected, the screening score is associated positively to a lower probability of progression, in particular its dimension related to the students themselves in contrast to the dimension rearding the family, the school and the region. However, most if not all screening score effects disappear when student performance variables are included (columns 3 and 6). This is to be expected to some extent given that the screening scores are largely based on the student's past schooling achievement but may also indicate that the latter indicators should carry even greater weight in assignment decisions.

It is also interesting to note the very strong effect of the number of failed modules in the first term of 2014/15 in explaining progression over that and the following academic year, with coefficients of $-7.6 \%$ in both specifications. Moreover, we find that fails in Portuguese prove to be a stronger predictor of progression results than fails in maths while fails in English have no predictive power at all. These differences across these three core modules may highlight the transversal nature of the main language - good performance in Portuguese will be of help in all other modules - as well as the relatively smaller importance of maths, perhaps because of the widespread poor performance in this subect (e.g. the $77 \%$ fail percentage in the first term of 2014/15 for signalled students and the $45 \%$ fail percentage in the case of non-signalled students, as indicated in Table 1).

We now turn our attention to the potential differences in the effects of EPIS across different groups of students. This question is relevant not only from the perspective of the robustness of the findings but also in terms of understanding the mechanisms of the effects documented 
above. Tables 5 presents the results, consider three key dimensions of possible heterogeneity in the impact of the program: gender, age and grade. Moreover, as before, we also consider the two measurements of the program application (assignment and delivery), for the benefit of robustness. In the case of the gender dimension, we find consistent evidence that EPIS is of greater benefit to girls than boys. The contrast is particularly striking in the more conservative assignment approach, in which the effect for girls increases to nearly 9 percentage points (significant at the $5 \%$ level) while the effect for boys become insignificant. When considering the case of delivery, the effect for boys is significant again and comparable to the benchmark estimates but the effects for girls nearly doubles to more than 13 percentage points. It is important to note that these EPIS effects are in addition to the general gender differences presented in Table 4, which already exhibit a significant independent head start for girls in terms of progression perspectives. In any case, these gender findings may follow from the non-cognitive dimension of the intervention. Alternatively, they may be related to the gender of the mediator, which in most cases are women, an hypothesis we investigate below.

A second dimension of analysis is age. Here we split our sample using the median value of 14 years exactly, as measured in September 2014. We find that older students benefit more from EPIS, with coefficients of .064 (assignment variable) and .122 (delivery). Similarly, students that start their participation in the program in the 8th grade (when they will be older, in most cases) tend to benefit more from it (columns 5 and 6 of Table 5) - .067 vs .027, in the case of the assignment variable. These two sets of findings may indicate that the noncognitive approach of EPIS is more suitable to older students. Taking these latter findings at face value, any expansion towards different age ranges, if following similar methodologies, would probably deliver better results if focused on upper secondary students in comparison their upper primary colleagues.

Our last robustness checks consider complementary outcomes variables to our benchmark measure of progression in both academic years (2014/15 and 2015/16). We now consider five alternative outcomes, presented in Table6; progression in year $1(2014 / 15)$, progression in year $2(2015 / 16$, indepedently of the outcome in year 1$)$, and year 2 pass results in three modules - maths, Portuguese and English. As before, we consider the two variants of the EPIS dummy variable (assignment and delivery). The results are, again, consistent across the specifications. They indicate that EPIS has a stronger impact on year 2 (and the impact 
in year 1 is generally negligible). This is consistent with the fact that the interventions only start in around March 2015 (i.e. three months before the end of the academic year) and the final grade of the year is determined taking into account the performance over the entire year. Moreover, the impact of EPIS is stronger in English and Portuguese (the latter to a less extent), while the effect in maths is either neglibible or positive, but in all cases smaller than in the cases of English and Portuguese. These findings may also highlight a relative weak potential of non-cognitive interventions is improving achievement of harder, cognitive-based subjects, such as maths, compared to language subjects. Again, these findings may highlight the cumulative nature of the program

\subsection{The role of the mediators}

Besides providing a detailed analysis of the effects of EPIS, we are also interested in learning more about the 'how' dimension, i.e. about the specific drivers that explain the sucess of the program. This has been achieved to some extent in the previous analyses, including through the consideration of different subgroups of students and different outcome variables. Here we focus on the specific contributions of mediators, who are a key part of the program, as they are exclusively responsible for the interventions with students. In particular, we consider a number of their characteristics to understand if those aspects may play a role in the achievement of students.

Table 7 presents descriptive statistics of these variables, across the up to 51 mediators for which these data are available. We find that the mediators are women in most cases $(91 \%)$ and that they are 48 years old on average. The mediators have participated in the program on average for 2.7 years, and that they spend $87 \%$ of their time on EPIS (the remaining being spent on standard teaching activities). The salaries of the mediators (as paid by the Ministry of Education) are 28,000 euros on average and 15\% have a postgraduate diploma. Finally, on average, their mediation load is of 58 students and $48 \%$ of their students are of the same gender. As indicated above, in almost all cases the gender identity of mediator and student will occur when the mediator is a woman given the predominance of the latter amongst the mediators.

We use this information to analyse the effects of mediators on student achievement by considering interactions between program participation and each mediator's caracteristics. It 
is important to note that there is no selection in the assignment of mediators to students, as in virtually all cases tehre is a single mediator per school. Moreover, the mediator is a teacher tat was already assigned to the school, even before the EPIS program started there. First we consider each dimension separately and finally we pool all interactions together. Table 8 presents the results, based on the delivery version of the EPIS dummy variable (similar qualitative results are found when using the assignment variable - available upon request). Considering the isolated interaction coefficients, the results indicate that, on top of the positive overall effects of EPIS mediation, none of the individual mediator characteristics have a positive effect on student progression. If anything, age, tenure and salary have negative effects. However, male mediators or mediators with postgraduate diplomas do not have significantly different results compared to women or mediators without postgraduate diplomas.

On the other hand, the interaction with a variable indicating cases in which the mediator is of the same gender as the student proves to have a positive effect. Moreover, the magnitude of the effect is of a similar scale as that of the EPIS effect itself in several specifications, with a coefficient of .046 (column 6). When pooling all interactions (column 7), it is this same-gender interaction the only that proves significant - all other variables (including age, tenure and salary) are insignificant - while its magnitude is also similar to the specification of column 6 (.063).

In other words, on top of the general EPIS effect, students appear to have better progression results if they are supported by mediators of the same gender. It is not the gender of the mediator that matters, it is whether the gender of the mediator is the same as the gender of the student. This finding contributes to an emerging literature on this issue, from the more general perspective of the role of teachers' gender. For instance, Dee (2007) finds that assignment to a same-gender teacher significantly improves the achievement of both girls and boys. However, the results in Antecol et al. (2015) indicate that female teachers lower some of the scores of female students but have no effect on male students (see also Carrell et al. (2010) and Fairlie et al. (2014)) ? $^{4}$

\footnotetext{
${ }^{4}$ These results are also consistent with anecdotal evidence from conversations with (female) mediators, who indicated they find it easier to engage with girls and results with boys usually take more time.
} 


\section{Conclusions}

This paper addresses the potential of interventions that focus on non-cognitive skills (Heckman \& Rubinstein 2001, Heckman et al. 2006, Kautz et al. 2014) to achieve improvement in student achievement. We present causal evidence about the effects of an original, large program entirely based on a non-cognitive approach, EPIS, that seeks to strengthen student achievement and reduce retention and early school leaving. EPIS is original also due to its screening of all the students in the participating schools, ensuring greater focus of the resources invested by the program - mostly the staff time, typically devoted to small-group or one-on-one sessions.

We explore the rich experimental and longitudinal data on all students collected by EPIS to identify the effects of the program upon student achievement. Our evidence indicates that, unlike many remedial, cognitive-based programs and even some non-cognitive based interventions, EPIS had a significantly positive effect in terms of improving the achievement levels of treated students. The probability that a student progresses over the two years increases by at least 10 percentage points. This effect increases to up to 20 percentage points in some specifications.

In this context, we find that the effect of the program is stronger amongst girls and older students as well as in language modules (compared to maths). Finally, we also find that while a number of mediator characteristics (including age, salary, postgraduate qualifications or experience with the program) does not appear to matter, the match between the gender of the mediator and that of the student plays an important role: girls (boys) benefit more from working with female (male) mediators.

Overall, our study supports the view that 'programs that enhance soft skills have an important place in an effective portfolio of public policies' (Heckman \& Kautz 2012). However, design, implementation and monitoring aspects will matter too, as other non-cognitive skills programs have not in all cases improved student achievement, especially in the case of adolescents (Holmlund \& Silva (2014), using quasi-experimental methods). 


\section{References}

Aaronson, D., Barrow, L. \& Sander, W. (2007), 'Teachers and student achievement in the Chicago public high schools', Journal of Labor Economics 25(1), 95-135.

Antecol, H., Eren, O. \& Ozbeklik, S. (2015), 'The Effect of Teacher Gender on Student Achievement in Primary School', Journal of Labor Economics 33(1), 63-89.

Banerjee, A. V., Cole, S., Duflo, E. \& Linden, L. (2007), 'Remedying education: Evidence from two randomized experiments in India', Quarterly Journal of Economics 122(3), 1235-1264.

Black, S. E. \& Devereux, P. J. (2011), Recent Developments in Intergenerational Mobility, Vol. 4 of Handbook of Labor Economics, Elsevier, chapter 16, pp. 1487-1541.

Carrell, S. E., Page, M. E. \& West, J. E. (2010), 'Sex and Science: How Professor Gender Perpetuates the Gender Gap', Quarterly Journal of Economics 125(3), 1101-1144.

Cortes, K. E., Goodman, J. S. \& Nomi, T. (2015), 'Intensive Math Instruction and Educational Attainment: Long-Run Impacts of Double-Dose Algebra', Journal of Human Resources 50(1), 108-158.

Dee, T. S. (2007), 'Teachers and the Gender Gaps in Student Achievement', Journal of Human Resources 42(3), 528-554.

Dobbie, W. \& Fryer, R. G. (2011), 'Are High-Quality Schools Enough to Increase Achievement among the Poor? Evidence from the Harlem Children's Zone', American Economic Journal: Applied Economics 3(3), 158-187.

Fairlie, R. W., Hoffmann, F. \& Oreopoulos, P. (2014), 'A Community College Instructor Like Me: Race and Ethnicity Interactions in the Classroom', American Economic Review 104(8), 2567-2591.

Glewwe, P. \& Kremer, M. (2006), Schools, Teachers, and Education Outcomes in Developing Countries, Vol. 2 of Handbook of the Economics of Education, Elsevier, chapter 16, pp. 9451017.

Hanushek, E. A., Schwerdt, G., Wiederhold, S. \& Woessmann, L. (2015), 'Returns to skills around the world: Evidence from PIAAC', European Economic Review 73(C), 103-130. 
Heckman, J. \& Carneiro, P. (2003), Human capital policy, NBER Working Papers 9495.

Heckman, J. \& Cunha, F. (2007), 'The technology of skill formation', American Economic Review $\mathbf{9 7}(2), 31-47$.

Heckman, J. J. \& Kautz, T. (2012), 'Hard evidence on soft skills', Labour Economics 19(4), 451-464.

Heckman, J. J. \& Rubinstein, Y. (2001), 'The importance of noncognitive skills: Lessons from the GED testing program', American Economic Review 91(2), 145-149.

Heckman, J. J., Stixrud, J. \& Urzua, S. (2006), 'The effects of cognitive and noncognitive abilities on labor market outcomes and social behavior', Journal of Labor Economics 24(3), 411482.

Holmlund, H. \& Silva, O. (2014), 'Targeting Noncognitive Skills to Improve Cognitive Outcomes: Evidence from a Remedial Education Intervention', Journal of Human Capital $8(2), 126-160$.

Jacob, B. A. \& Lefgren, L. (2004), 'Remedial education and student achievement: A regression-discontinuity analysis', Review of Economics and Statistics 86(1), 226-244.

Kautz, T., Heckman, J. J., Diris, R., ter Weel, B. \& Borghans, L. (2014), Fostering and Measuring Skills: Improving Cognitive and Non-Cognitive Skills to Promote Lifetime Success, OECD Report.

Krueger, A. B. \& Lindahl, M. (2001), 'Education for growth: Why and for whom?', Journal of Economic Literature 39(4), 1101-1136.

Lavy, V. (2009), 'Performance pay and teachers effort, productivity and grading ethics', American Economic Review 99, 1979-2011.

Lavy, V. \& Schlosser, A. (2005), 'Targeted remedial education for underperforming teenagers: Costs and benefits', Journal of Labor Economics 23(4), 839-874.

Lazear, E. P. (2001), 'Educational production', Quarterly Journal of Economics 116(3), 777803.

Lazear, E. P. (2003), 'Teacher incentives', Swedish Economic Policy Review 10(2), 179-214. 
Leuven, E., Lindahl, M., Oosterbeek, H. \& Webbink, D. (2007), 'The effect of extra funding for disadvantaged pupils on achievement', Review of Economics and Statistics 89(4), 721-736.

Machin, S., McNally, S. \& Meghir, C. (2004), 'Improving pupil performance in English secondary schools: Excellence in cities', Journal of the European Economic Association 2(23), 396-405.

Martins, P. S. (2017), Can Non-Cognitive Skills Programs Improve Achievement? QuasiExperimental Evidence from EPIS, Queen Mary University of London, mimeo.

Martins, P. S. \& Walker, I. (2006), Student achievement and university classes: Effects of attendance, size, peers, and teachers, IZA Discussion Paper 2490.

Pereira, A. I., Goes, A. R., Ferreira, A. J., da Silva, C. F., Rijo, D., Barros, L. \& Nossa, P. (2008), Trabalhar para o sucesso escolar: Manual para técnicos /Working towards student achievement: A manual for technical staff], Texto Editora/EPIS.

Rivkin, S. G., Hanushek, E. A. \& Kain, J. F. (2005), 'Teachers, schools, and academic achievement', Econometrica 73(2), 417-458.

Taylor, E. (2014), 'Spending more of the school day in math class: Evidence from a regression discontinuity in middle school', Journal of Public Economics 117(C), 162-181. 


\section{Figures}

Figure 1: A mediation session

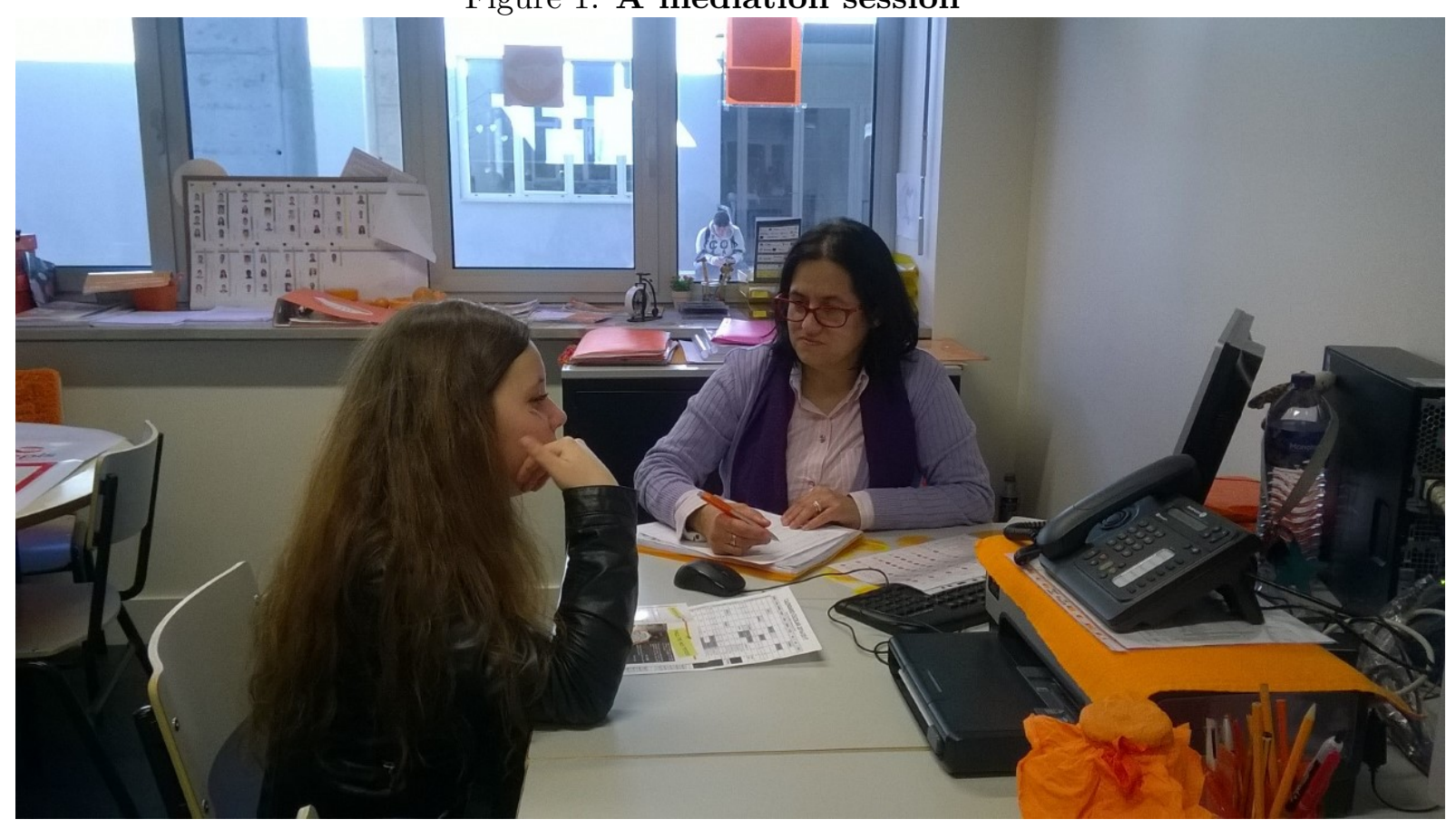

Notes: An illustration of a one-to-one mediation session in a participating school. 
Figure 2: Signalled and treated students

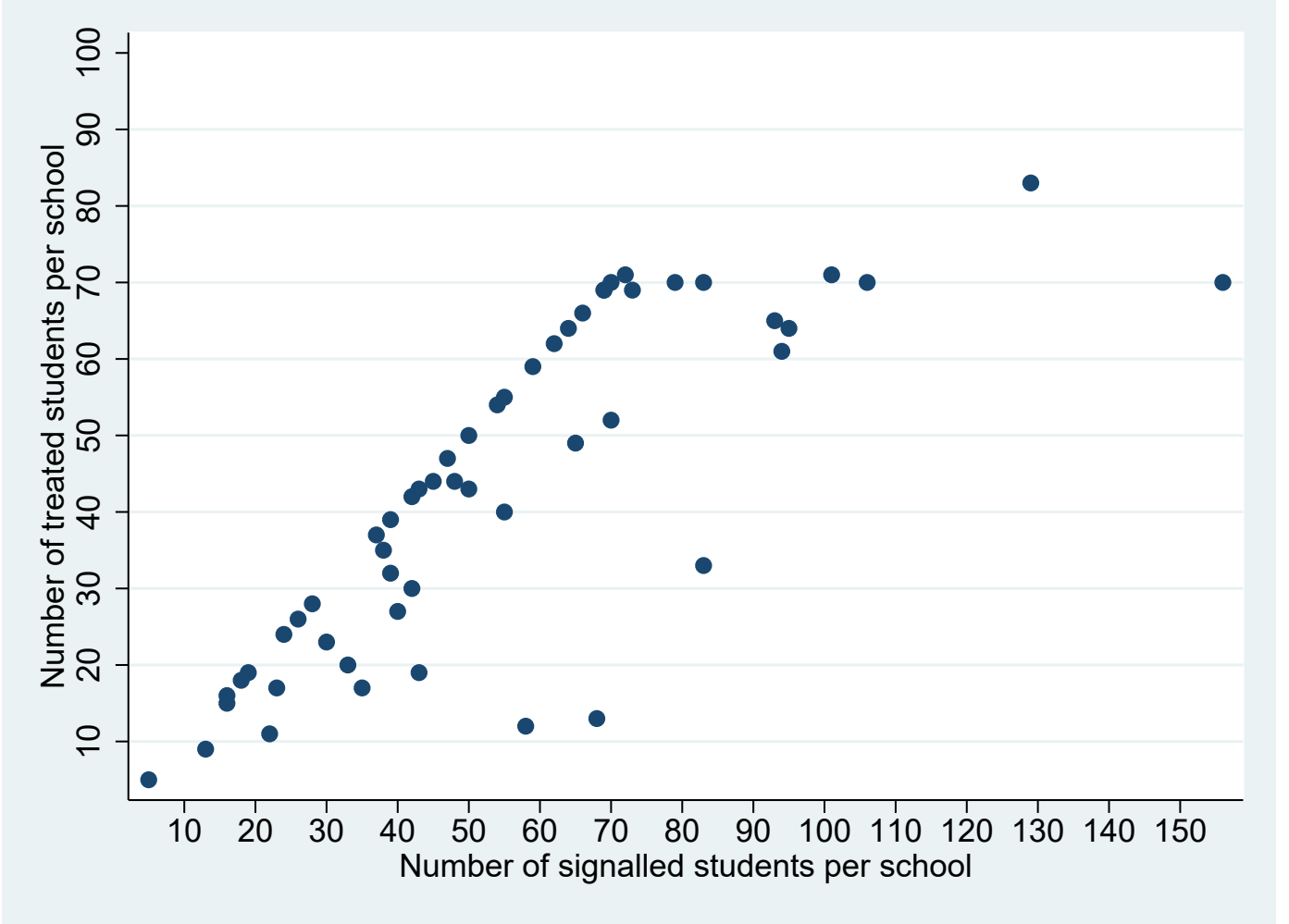

Notes: The horizontal axis indicates the number of students per school that are signalled following the screening process while the vertical axis indicates the number of students per school that are treated. Each dot corresponds to a different school. 2,079 out of the total of 2,959 students are in schools where the two numbers (signalled and treated) do not match (i.e. there are more signalled than treated students). In this case, the students that are treated in tho schools are selected randomly out of the full set of signalled students. 


\section{Tables}

Table 1: Descriptive statistics: treatment and control groups

\begin{tabular}{lcccccc}
\hline \hline & \multicolumn{2}{c}{$(1)$} & \multicolumn{2}{c}{$(2)$} & \multicolumn{2}{c}{$(3)$} \\
& Treatment group & \multicolumn{2}{c}{ Control group } & \multicolumn{2}{c}{ Differences } \\
& mean & sd & mean & sd & b & t \\
\hline Age & 14.19 & 1.38 & 14.23 & 1.48 & 0.04 & $(0.60)$ \\
Female & 0.46 & 0.50 & 0.49 & 0.50 & 0.03 & $(1.52)$ \\
Class size & 22.28 & 4.31 & 22.39 & 4.16 & 0.11 & $(0.57)$ \\
Vocational class & 0.12 & 0.32 & 0.21 & 0.41 & $0.09^{* * *}$ & $(4.84)$ \\
Academic year & 2014.00 & 0.00 & 2014.00 & 0.00 & 0.00 & $()$. \\
School year & 7.50 & 0.57 & 7.49 & 0.50 & -0.01 & $(-0.63)$ \\
Screening - Student & 11.86 & 3.66 & 12.13 & 3.69 & 0.27 & $(1.67)$ \\
Screening - Family & 1.35 & 0.94 & 1.38 & 0.96 & 0.02 & $(0.56)$ \\
Screening - School & 10.16 & 4.40 & 10.44 & 4.40 & 0.28 & $(1.45)$ \\
Screening - Graffar & 3.34 & 0.70 & 3.51 & 0.65 & $0.17^{* * *}$ & $(5.88)$ \\
No. fail grades 2014:q1 & 4.80 & 2.35 & 4.80 & 2.30 & -0.01 & $(-0.05)$ \\
Fail in maths 2014:q1 & 0.78 & 0.42 & 0.74 & 0.44 & -0.03 & $(-1.62)$ \\
Fail in Portuguese 2014:q1 & 0.59 & 0.49 & 0.56 & 0.50 & -0.03 & $(-1.37)$ \\
Fail in English 2014:q1 & 0.50 & 0.50 & 0.52 & 0.50 & 0.02 & $(0.66)$ \\
No. fail grades 2014:q2 & 4.37 & 2.57 & 4.43 & 2.63 & 0.06 & $(0.43)$ \\
Fail in maths 2014:q2 & 0.75 & 0.43 & 0.73 & 0.45 & -0.02 & $(-1.07)$ \\
Fail in Portuguese 2014:q2 & 0.52 & 0.50 & 0.50 & 0.50 & -0.01 & $(-0.55)$ \\
Fail in English 2014:q2 & 0.49 & 0.50 & 0.48 & 0.50 & -0.01 & $(-0.41)$ \\
\hline Observations & 2311 & & 648 & & 2959 & \\
\hline \hline
\end{tabular}

Notes: The table presents descriptive statistics of the treatment and control groups of students and a statistical analysis of the differences in their means. The variables considered are the following: 'Class size' denotes the number of students in the class; 'Vocational class' is a dummy for vocational education classes; 'Academic year' is 2014 (in the case of the 2014/15 academic year) or 2015 (2015/16); 'School year' can be 7th, 8th or 9th grades; 'Screening' refers to a score of different dimensions of each student, regarding the probability of poor performance (the student, their family, school and region); 'No. fail grades 2014:q1' indicates how many modules are failed (out of a maximum of 12) in the first term of the first academic year; 'Fail in maths 2014:q1' is a dummy variable equal to one if the student fails the maths module in the first term, and similarly for the other modules (Portuguese and English) and the second term of the first academic year. 
Table 2: Descriptive statistics: signalled and non-signalled students

\begin{tabular}{lcccccc}
\hline \hline & \multicolumn{2}{c}{$(1)$} & \multicolumn{3}{c}{$(2)$} & \multicolumn{2}{c}{$(3)$} \\
& \multicolumn{2}{c}{$\begin{array}{c}\text { Signalled group } \\
\text { mean }\end{array}$} & sd & \multicolumn{2}{c}{ Non-signalled group } & \multicolumn{2}{c}{ Differences } \\
& 14.20 & 1.40 & 13.34 & 1.29 & $-0.85^{* * *}$ & $(-27.92)$ \\
\hline Age & 0.47 & 0.50 & 0.50 & 0.50 & $0.03^{* *}$ & $(2.94)$ \\
Female & 22.30 & 4.28 & 23.72 & 4.25 & $1.42^{* * *}$ & $(15.18)$ \\
Class size & 0.14 & 0.34 & 0.05 & 0.22 & $-0.09^{* * *}$ & $(-11.60)$ \\
Vocational class & 2014.00 & 0.00 & 2014.00 & 0.00 & 0.00 & $()$. \\
Academic year & 7.50 & 0.55 & 7.44 & 0.51 & $-0.07^{* * *}$ & $(-5.52)$ \\
School year & 11.92 & 3.67 & 4.43 & 4.17 & $-7.49^{* * *}$ & $(-80.81)$ \\
Screening score - Student & 1.36 & 0.94 & 0.83 & 0.64 & $-0.53^{* * *}$ & $(-26.83)$ \\
Screening score - Family & 10.22 & 4.40 & 8.74 & 4.01 & $-1.47^{* * *}$ & $(-14.54)$ \\
Screening score - School & 3.37 & 0.69 & 2.86 & 0.77 & $-0.51^{* * *}$ & $(-29.67)$ \\
Screening score - Graffar & 4.80 & 2.34 & 1.89 & 2.28 & $-2.91^{* * *}$ & $(-53.73)$ \\
No. fail grades 2014:q1 & 0.77 & 0.42 & 0.39 & 0.49 & $-0.38^{* * *}$ & $(-36.50)$ \\
Fail in maths 2014:q1 & 0.59 & 0.49 & 0.24 & 0.43 & $-0.35^{* * *}$ & $(-31.16)$ \\
Fail in Portuguese 2014:q1 & 0.50 & 0.50 & 0.20 & 0.40 & $-0.30^{* * *}$ & $(-26.70)$ \\
Fail in English 2014:q1 & 4.39 & 2.58 & 1.86 & 2.38 & $-2.52^{* * *}$ & $(-42.50)$ \\
No. fail grades 2014:q2 & 0.74 & 0.44 & 0.38 & 0.49 & $-0.36^{* * *}$ & $(-33.97)$ \\
Fail in maths 2014:q2 & 0.51 & 0.50 & 0.20 & 0.40 & $-0.31^{* * *}$ & $(-27.54)$ \\
Fail in Portuguese 2014:q2 & 0.49 & 0.50 & 0.21 & 0.41 & $-0.27^{* * *}$ & $(-24.16)$ \\
Fail in English 2014:q2 & 0.49 & & 10014 & \\
\hline Observations & 2959 & & 7055 & & & \\
\hline \hline
\end{tabular}

Notes: The table presents descriptive statistics of the treatment and control (signalled) groups of students, on the one hand, and non-signalled students, on the other hand, as well as a statistical analysis of the differences in their means. The variables considered are the same as those described in Table 1. 
Table 3: Main results: impact of EPIS on progression

\begin{tabular}{lcccc}
\hline \hline & $(1)$ & $(2)$ & $(3)$ & $(4)$ \\
& $\begin{array}{c}\text { All } \\
\text { observations }\end{array}$ & $\begin{array}{c}\text { Students observed } \\
\text { in the two years }\end{array}$ & $\begin{array}{c}\text { All } \\
\text { observations }\end{array}$ & $\begin{array}{c}\text { Students treated } \\
\text { or not assigned }\end{array}$ \\
\hline EPIS (assignment) & .048 & .048 & & \\
& $(.025)^{*}$ & $(.026)^{*}$ & & .061 \\
EPIS (delivery) & & & .099 & $(.026)^{* *}$ \\
Obs. & & & $(.023)^{* * *}$ & 2808 \\
$R^{2}$ & 2959 & 2657 & 2959 & .076 \\
\hline \hline
\end{tabular}

Notes: The dependent variable is a dummy variable equal to one if the student progresses in both years (7th and 8th, or 8th and 9th). 'EPIS (assignment)' is a dummy variable equal to one if the student is randomly assigned to treatment. 'EPIS (delivery)' is a dummy variable equal to one if the student assigned to treatment receives the intervention. 'Students treated or not assigned' corresponds to the full sample except student assigned to treatment but that do not receive the intervention. All specifications include school fixed effects. One observation for each student. Significance levels: *: $0.1 ; * *: 0.05 ; * * *: 0.01$. 
Table 4: Robustness checks: impact of EPIS on progression, with control variables

\begin{tabular}{|c|c|c|c|c|c|c|}
\hline & $(1)$ & $(2)$ & $(3)$ & $(4)$ & $(5)$ & (6) \\
\hline EPIS (assignment) & $\begin{array}{c}.053 \\
(.025)^{* *}\end{array}$ & $\begin{array}{c}.054 \\
(.024)^{* *}\end{array}$ & $\begin{array}{c}.077 \\
(.026)^{* * * *}\end{array}$ & & & \\
\hline EPIS (delivery) & & & & $\begin{array}{c}.097 \\
(.023)^{* * * *}\end{array}$ & $\begin{array}{c}.086 \\
(.023)^{* * *}\end{array}$ & $\begin{array}{c}.088 \\
(.024)^{* * *}\end{array}$ \\
\hline Female & $\begin{array}{c}.052 \\
(.018)^{* * *}\end{array}$ & $\begin{array}{l}.023 \\
(.017)\end{array}$ & $\begin{array}{c}.049 \\
(.018)^{* * *}\end{array}$ & $\begin{array}{c}.053 \\
(.018)^{* * * *}\end{array}$ & $\begin{array}{l}.024 \\
(.017)\end{array}$ & $\begin{array}{c}.050 \\
(.018)^{* * *}\end{array}$ \\
\hline Age & $\begin{array}{l}.059 \\
(.112)\end{array}$ & $\begin{array}{l}.169 \\
(.109)\end{array}$ & $\begin{array}{l}.146 \\
(.123)\end{array}$ & $\begin{array}{l}.042 \\
(.112)\end{array}$ & $\begin{array}{l}.153 \\
(.109)\end{array}$ & $\begin{array}{l}.126 \\
(.123)\end{array}$ \\
\hline $\operatorname{Age}^{2} / 100$ & $\begin{array}{l}-.412 \\
(.386)\end{array}$ & $\begin{array}{l}-.624 \\
(.375)^{*}\end{array}$ & $\begin{array}{r}-.688 \\
(.428)\end{array}$ & $\begin{array}{l}-.347 \\
(.386)\end{array}$ & $\begin{array}{l}-.566 \\
(.375)\end{array}$ & $\begin{array}{l}-.613 \\
(.428)\end{array}$ \\
\hline 8th grade & $\begin{array}{c}.135 \\
(.021)^{* * * *}\end{array}$ & $\begin{array}{c}.110 \\
(.021)^{* * *}\end{array}$ & $\begin{array}{c}.086 \\
(.022)^{* * * *}\end{array}$ & $\begin{array}{c}.133 \\
(.021)^{* * * *}\end{array}$ & $\begin{array}{c}.109 \\
(.021)^{* * * *}\end{array}$ & $\begin{array}{c}.084 \\
(.022)^{* * *}\end{array}$ \\
\hline Class size & $\begin{array}{c}-.014 \\
(.003)^{* * *}\end{array}$ & $\begin{array}{c}-.014 \\
(.003)^{* * *}\end{array}$ & $\begin{array}{c}-.006 \\
(.003)^{* *}\end{array}$ & $\begin{array}{c}-.014 \\
(.003)^{* * *}\end{array}$ & $\begin{array}{c}-.015 \\
(.003)^{* * *}\end{array}$ & $\begin{array}{l}-.007 \\
(.003)^{* *}\end{array}$ \\
\hline Screening score - Student & & $\begin{array}{c}-.038 \\
(.003)^{* * *}\end{array}$ & $\begin{array}{l}-.003 \\
(.004)\end{array}$ & & $\begin{array}{l}-.037 \\
(.003)^{* * *}\end{array}$ & $\begin{array}{l}-.002 \\
(.004)\end{array}$ \\
\hline Screening score - Family & & $\begin{array}{l}.009 \\
(.009)\end{array}$ & $\begin{array}{l}.002 \\
(.010)\end{array}$ & & $\begin{array}{l}.009 \\
(.009)\end{array}$ & $\begin{array}{l}.002 \\
(.010)\end{array}$ \\
\hline Screening score - School & & $\begin{array}{l}-.004 \\
(.002)^{*}\end{array}$ & $\begin{array}{l}-.004 \\
(.002)^{*}\end{array}$ & & $\begin{array}{l}-.003 \\
(.002)\end{array}$ & $\begin{array}{l}-.004 \\
(.002)^{*}\end{array}$ \\
\hline Screening score - Graffar & & $\begin{array}{l}-.018 \\
(.014)\end{array}$ & $\begin{array}{l}-.020 \\
(.014)\end{array}$ & & $\begin{array}{l}-.018 \\
(.014)\end{array}$ & $\begin{array}{r}-.020 \\
(.014)\end{array}$ \\
\hline No. fail grades 2014:q1 & & & $\begin{array}{c}-.076 \\
(.007)^{* * *}\end{array}$ & & & $\begin{array}{c}-.076 \\
(.007)^{* * *}\end{array}$ \\
\hline Fail in maths 2014:q1 & & & $\begin{array}{l}-.048 \\
(.025)^{*}\end{array}$ & & & $\begin{array}{l}-.051 \\
(.025)^{* *}\end{array}$ \\
\hline Fail in Portuguese 2014:q1 & & & $\begin{array}{l}-.061 \\
(.022)^{* * *}\end{array}$ & & & $\begin{array}{c}-.060 \\
(.022)^{* * *}\end{array}$ \\
\hline Fail in English 2014:q1 & & & $\begin{array}{l}-.003 \\
(.021)\end{array}$ & & & $\begin{array}{c}-.003 \\
(.021)\end{array}$ \\
\hline Obs. & 2936 & 2936 & 2390 & 2936 & 2936 & 2390 \\
\hline$R^{2}$ & .117 & .173 & .286 & .121 & .176 & .288 \\
\hline
\end{tabular}

Notes: The dependent variable is a dummy variable equal to one if the student progresses in both years (7th and 8th, or 8th and 9th). 'EPIS (assignment)' is a dummy variable equal to one if the student is randomly assigned to treatment. 'EPIS (delivery)' is a dummy variable equal to one if the student assigned to treatment receives the intervention. '8th grade' is a dummy equal to one for students that started their involvement in the program when they were attending the 8th grade. 'Class size' is the number of students in the class (first year). 'Screening scores' measure the potential challenges faced by each student in terms of progression (higher score, less likely to progress) from a number of indicators and questions. 'No. fail grades 2014:q1' indicates the number of modules failed by the student in the first term of the first year (before participation in the programme). 'Fail in maths 2014:q1' is a dummy variable equal to one if the student did not pass maths in the first term of the first year (grade one or two, in contrast to grades three, four or five). All specifications include school fixed effects. One observation for each student. Significance levels: *: $0.1 ; * *: 0.05 ; * * *: 0.01$. 
Table 5: Robustness checks: impact of EPIS on progression, different subgroups

\begin{tabular}{|c|c|c|c|c|c|c|}
\hline & Girls & (2) & $\begin{array}{c}(3) \\
14 \text { or } \\
\text { younger }\end{array}$ & $\begin{array}{c}(4) \\
\text { Older } \\
\text { than } 14\end{array}$ & $\begin{array}{c}(5) \\
7 \text { th grade }\end{array}$ & $\begin{array}{c}\text { (6) } \\
\text { 8th grade }\end{array}$ \\
\hline EPIS (assignment) & $\begin{array}{l}.087 \\
(.037)^{* *}\end{array}$ & $\begin{array}{l}.007 \\
(.035)\end{array}$ & $\begin{array}{l}.014 \\
(.036)\end{array}$ & $\begin{array}{l}.064 \\
(.035)^{*}\end{array}$ & $\begin{array}{l}.027 \\
(.034)\end{array}$ & $\begin{array}{l}.067 \\
(.037)^{*}\end{array}$ \\
\hline $\begin{array}{l}\text { Obs. } \\
R^{2}\end{array}$ & $\begin{array}{l}1383 \\
.104 \\
\end{array}$ & $\begin{array}{r}1576 \\
.093 \\
\end{array}$ & $\begin{array}{l}1445 \\
.121 \\
\end{array}$ & $\begin{array}{c}1514 \\
.11 \\
\end{array}$ & $\begin{array}{l}1638 \\
.112 \\
\end{array}$ & $\begin{array}{l}1321 \\
.105 \\
\end{array}$ \\
\hline EPIS (delivery) & $\begin{array}{c}.134 \\
(.034)^{* * *}\end{array}$ & $\begin{array}{c}.066 \\
(.033)^{* *}\end{array}$ & $\begin{array}{l}.048 \\
(.034)\end{array}$ & $\begin{array}{c}.122 \\
(.032)^{* * *}\end{array}$ & $\begin{array}{c}.082 \\
(.032)^{* * *}\end{array}$ & $\begin{array}{c}.109 \\
(.035)^{* * *}\end{array}$ \\
\hline $\begin{array}{l}\text { Obs. } \\
R^{2}\end{array}$ & $\begin{array}{c}1383 \\
.11\end{array}$ & $\begin{array}{l}1576 \\
.095\end{array}$ & $\begin{array}{l}1445 \\
.122\end{array}$ & $\begin{array}{l}1514 \\
.117\end{array}$ & $\begin{array}{l}1638 \\
.116\end{array}$ & $\begin{array}{l}1321 \\
.109\end{array}$ \\
\hline
\end{tabular}

Notes: The dependent variable is a dummy variable equal to one if the student progresses in both years (7th and 8th, or 8th and 9th). 'EPIS (assignment)' is a dummy variable equal to one if the student is randomly assigned to treatment. 'EPIS (delivery)' is a dummy variable equal to one if the student assigned to treatment receives the intervention. 'Older than 14' refers to students that are 14 and one month or older as of September 2014 (the beginning of the first term of 2014/15, the academic year in which the program is first implemented). '7th grade' indicates students that start their participation in the program in that grade. All specifications include school fixed effects. One observation for each student. Significance levels: *: 0.1 ; **: 0.05 ; ***: 0.01 . 
Table 6: Robustness checks: impact of EPIS, different outcomes

\begin{tabular}{lccccc}
\hline \hline & $(1)$ & $(2)$ & $(3)$ & $(4)$ & $(5)$ \\
& Year 1 & Year 2 & & Year 2 pass \\
& \multicolumn{2}{c}{ progression } & Maths & Portuguese & English \\
\hline EPIS (assignment) & .003 & .064 & .016 & .045 & .070 \\
& $(.024)$ & $(.025)^{* * *}$ & $(.021)$ & $(.025)^{*}$ & $(.025)^{* * *}$ \\
Obs. & 2657 & 2657 & 2959 & 2959 & 2959 \\
$R^{2}$ & .096 & .07 & .095 & .122 & .096 \\
\hline \hline & & & & .103 & .126 \\
\hline EPIS (delivery) & .026 & .097 & .050 & $(.023)^{* * *}$ & $(.023)^{* * *}$ \\
& $(.023)$ & $(.024)^{* * *}$ & $(.020)^{* *}$ & 2959 & 2959 \\
Obs. & 2657 & 2657 & 2959 & .127 & .103 \\
$R^{2}$ & .097 & .074 & .096 & & \\
\hline \hline
\end{tabular}

Notes: The dependent variable in the first (second) column is a dummy variable equal to one if the student progresses in the first (second) year of program participation. The dependent variable in the third (fourth, fifth) column is a dummy variable equal to one if the student passes her maths (Portuguese, English) module. 'EPIS (assignment)' is a dummy variable equal to one if the student is randomly assigned to treatment. 'EPIS (delivery)' is a dummy variable equal to one if the student assigned to treatment receives the intervention. All specifications include school fixed effects. One observation for each student. Significance levels: *: $0.1 ; * *: 0.05 ; * *$ : 0.01 . 
Table 7: Descriptive statistics: the mediators

\begin{tabular}{lcc}
\hline \hline & Mean & SD \\
\hline Male & .09 & .28 \\
Age & 48.21 & 5.44 \\
Tenure & 2.74 & 1.75 \\
Share of time in EPIS & 0.87 & 0.22 \\
Annual gross salary (in euros) & 28051.63 & 4275.70 \\
Postgraduate degree holder & 0.15 & 0.36 \\
Mediation load (number of students supported) & 58.02 & 29.59 \\
Percentage of supported students of same gender & .48 & .05 \\
\hline Observations & 34 & \\
\hline \hline
\end{tabular}

Notes: 'Male' is a dummy variable equal to one if the student's mediator is a man. 'Age (Tenure, Annual gross salary)' is the age (tenure, salary) of the mediator. 'Share of time in EPIS' is the percentage of time spent by the mediator on EPIS (in terms of their full-time contract), e.g. 50\%. 'PG diploma' is a dummy variable equal to one if the mediator has a postgraduate degree. 'Mediation load' is the number of students supported by the mediator. 'Percentage of supported students of same gender' measures the percentage of male (female) students in the case of a male (female) mediator. 
Table 8: The role of the mediators and their characteristics

\begin{tabular}{lccccccc}
\hline \hline & $(1)$ & $(2)$ & $(3)$ & $(4)$ & $(5)$ & $(6)$ & $(7)$ \\
\hline EPIS (delivery) & .110 & .293 & .170 & .279 & .114 & .093 & .297 \\
& $(.027)^{* * *}$ & $(.062)^{* * *}$ & $(.039)^{* * *}$ & $(.060)^{* * *}$ & $(.028)^{* * *}$ & $(.028)^{* * *}$ & $(.062)^{* * *}$
\end{tabular}

Interactions: EPIS x ... mediator characteristics

\begin{tabular}{|c|c|c|c|c|c|c|c|}
\hline Male & $\begin{array}{c}-.003 \\
(.222)\end{array}$ & & & & & & $\begin{array}{l}.083 \\
(.228)\end{array}$ \\
\hline Age & & $\begin{array}{c}-.005 \\
(.001)^{* * *}\end{array}$ & & & & & $\begin{array}{r}-.007 \\
(.006)\end{array}$ \\
\hline Tenure & & & $\begin{array}{l}-.026 \\
(.012)^{* *}\end{array}$ & & & & $\begin{array}{r}-.007 \\
(.014)\end{array}$ \\
\hline Salary & & & & $\begin{array}{c}-.008 \\
(.002)^{* * *}\end{array}$ & & & $\begin{array}{l}.003 \\
(.009)\end{array}$ \\
\hline PG diploma & & & & & $\begin{array}{r}-.062 \\
(.113)\end{array}$ & & $\begin{array}{l}-.008 \\
(.114)\end{array}$ \\
\hline Same-gender & & & & & & $\begin{array}{c}.046 \\
(.025)^{*}\end{array}$ & $\begin{array}{c}.063 \\
(.026)^{* *}\end{array}$ \\
\hline Obs. & 2081 & 1998 & 2081 & 1998 & 2081 & 2081 & 1998 \\
\hline$R^{2}$ & .073 & .077 & .075 & .076 & .073 & .074 & .08 \\
\hline
\end{tabular}

Notes: The dependent variable is a dummy variable equal to one if the student progresses in both years (7th and 8th, or 8th and 9th). 'EPIS (delivery)' is a dummy variable equal to one if the student assigned to treatment receives the intervention. 'EPIS x Male mediator' is an interaction between the EPIS dummy and a dummy variable equal to one if the student's mediator is a man. 'EPIS x Mediator age (tenure, salary)' is an interaction between the EPIS dummy and the age (tenure, salary) of the student's mediator. 'EPIS x Mediator PG diploma (Same-gender mediator)' is an interaction between the EPIS dummy and a dummy variable equal to one if the student's mediator has a postgraduate degree (has the same gender as the student). All specifications include school fixed effects. One observation for each student. Significance levels: *: $0.1 ; * *: 0.05 ; * * *: 0.01$. 